\title{
Research on the Mode of Tea Marketing Channel Alliance with Professional Cooperatives as the Core
}

\author{
Song Chen \\ College of Economic, Fujian Agriculture and Forestry \\ University, China Fuzhou 350002 \\ Wuyi University, China Wuyishan 354300
}

\author{
Jiangfan Yang \\ College of Economic, Fujian Agriculture and Forestry \\ University, China Fuzhou 350002
}

\begin{abstract}
In order to clarify the operation mode of tea cooperatives, this paper constructs the overall operation framework of tea marketing channel alliance model with cooperatives as the core through literature review and field investigation. Among them, the horizontal alliance includes the cooperative alliance organized by farmers spontaneously, the tea professional cooperatives in the form of tea group, the leading tea enterprises set up cooperatives, the cooperative alliance is composed of tea professional cooperatives. And the vertical alliance includes Tea professional cooperatives (or union) and tea processing enterprises, Tea wholesalers wholesalers / (market) market / and Tea retail terminal alliance. Compared with the previous literature, this paper systematically combs the mode of tea marketing channel alliance with professional cooperatives as the core, and the division of horizontal alliance and vertical alliance for the first time is an extension and development of the previous literature.
\end{abstract} mode

Keywords-Tea; Cooperative; Marketing channel; Alliance

\section{INTRODUCTION}

Tea industry has become an important pillar industry in 21 major producing provinces and an important source of income for more than 8,000 million farmers [1]. China has 80 million tea farmers, they are long in a small scale and decentralized state, while unable to participate in the tea circulation of other value-added links, leading to poor farmers negotiations, tea farmers in the market transactions in a disadvantageous position [2]. In this context, the development of tea professional cooperatives is to improve the status of tea farmers market and bargaining power of the important choice, also is an important measure to strengthen the market competitiveness of tea industry, and an important way to increase the tea farmers' income. Tea professional cooperatives is the organization of tea farmers to develop production and an important bridge to the market, On the one hand, tea farmers cooperatives can organize tea farmers, according to market demand, the use of local resources, in accordance with uniform standards and requirements around the leading industries, the development of high quality, safe and efficient agricultural products, to create a unified brand; On the other hand, tea cooperatives can concentrate the scattered tea products on the market and enhance the market competitiveness. At the same time, it can effectively resolve the possible market winds of decentralized operations, improve the sales price of agricultural products and improve the economic benefits, and effectively increase the income of farmers. In the market and the government to encourage the dual drive, the Chinese tea professional cooperatives have been rapid development, tea professional cooperatives as the core of the marketing channel alliance model has also been innovative. In view of this, this paper through the literature review and Fujian Province and China's main tea producing areas of the field research, combing the professional cooperatives as the core of the tea marketing channel alliance of the main model to build a cooperative as the core of the tea marketing channel alliance model of the overall operation, Having a certain practical significance [3].

\section{THE CONNOTATION OF THE ALLIANCE MODE OF TEA MARKETING CHANNEL WITH PROFESSIONAL COOPERATIVES AS THE CORE}

Tea professional cooperatives are based on the family contract management, engaged in tea production of tea farmers based on "voluntary join, free to withdraw, democratic management, the return of the surplus" principle, in accordance with the common negotiations of the charter to co-production, management and services of the mutual aid of tea industry economic organizations [4]. Tea professional cooperatives with its members as the main target, to provide members of the tea production materials to buy, production technology guidance, tea processing, transportation, storage, sales and production and management of tea-related technology and information services. And cooperatives as the core of the tea marketing channel alliance is in the entire tea sales channels, tea marketing channels in some independent channel members (mainly tea farmers, tea cooperatives, tea enterprises, tea wholesalers / market, tea retailers Etc.) on the basis of mutual trust and common long-term goal, to cooperatives as the core, in the front by the tea farmers (tea group) set up production alliance (horizontal alliance), in the backward and tea enterprises, wholesalers, retail terminal distribution Alliance (vertical union), through some form (contract, equity, etc.) and the formation of the advantages of complementary, risk sharing, benefit sharing of the organizational system. 


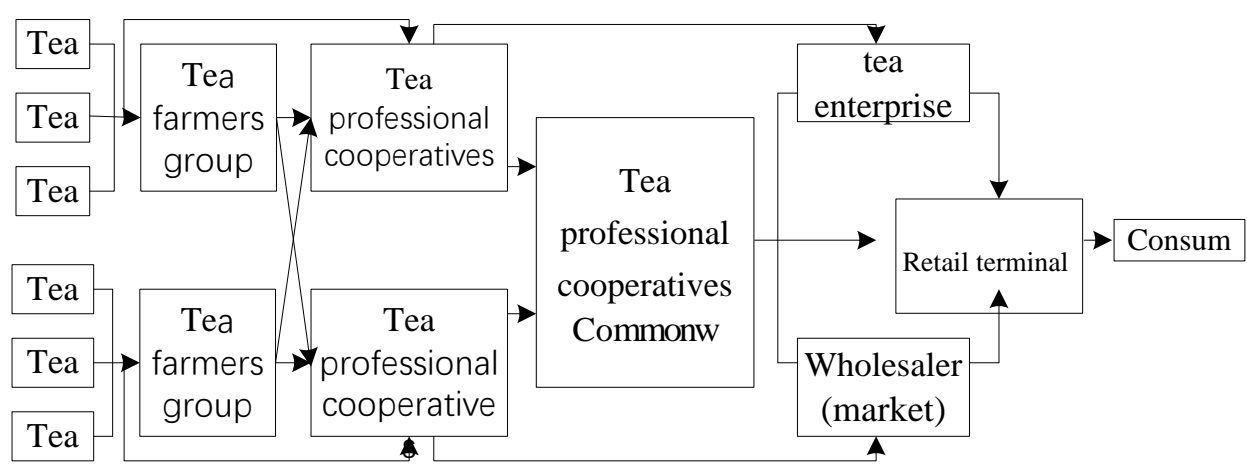

Fig. 1. Cooperative as the core of the tea marketing channel alliance mode of the operating framework

\section{AN ANALYSIS OF HORIZONTAL ALLIANCE OF TEA Marketing Channel AlLiance Mode}

\section{A. Tea farmers spontaneously organize tea professional cooperatives}

Tea farmers spontaneous organization of the Union of tea professional cooperatives generally led by the local tea tycoon. In the process of production and operation, the members of cooperatives, due to endogenous (their own development needs) or exogenous (policy guidance) forces to produce the motive of the formation of cooperative economic organizations, the loose tea farmers together to form tea production, processing, Sales as one of the alliance [5]. For example, the Long Juan Township, Anxi County, Fujian Province, the source of tea professional cooperatives is to Chen Binghuai, Liu Jinlong, Chen Chuanxi three tea tycoons led the formation of tea cooperatives, was established in July 2008, members from the initial 29 to the development of 158 The price from the initial 20 yuan / kg increased to 200 yuan / kg, high or even more than 500 yuan / kg, 2013 sales revenue reached more than 3,000 million, the price of tea, Members of the income of $80,000-9$ million yuan is not a minority.

\section{B. Tea farmers group spontaneously organized tea professional cooperatives}

The tea professional cooperatives are not distributed by the farmers to join the cooperatives, but by a number of tea farmers voluntarily form a joint security group, and then by the joint security team to apply for co-operatives into the community. This kind of tea cooperatives should organize and implement the management responsibilities of the "joint management system" base, and implement the unified "unified agricultural procurement", unified agricultural distribution, unified agricultural use guidance, unified agricultural activities record, unified brand sales Cooperation mode of operation, to further improve the joint system model. For example, the Anxi County, Fujian Province, Huqiu Town, the United States Zhuang tea professional cooperatives was established in March 2008, mainly by the village of 5-10 households tea farmers voluntarily formed a joint security group, the group to the cooperatives to join the agency; the cooperative joint protection Group of 33, 233 tea farmers joined the cooperatives, the number of households accounted for $82.3 \%$ of the total number of households. The cooperatives in February 2010 the United States Zhuang tea professional cooperatives were named Anxi "Top Ten" cooperatives, in June 2013 by the municipal government awarded the "municipal demonstration of farmer professional cooperatives."

\section{Tea leading enterprises to lead the formation of coalition cooperatives}

This kind of cooperatives mainly form the "enterprise + cooperatives + farmers" tea alliance business model [6]. The tea cooperatives are mainly composed of "tea cooperatives", which are formed by the strong tea enterprises. For example, Anxi County Crown Tea Factory led the formation of Fujian Province Anxi County town of three security tea professional cooperatives in September 2008 to set up the initial registered capital of 60,000, has been added to 2 million.Tea garden area per household to 6 acres of tea garden shares, the existing members of 500 people (households), a total of 3,000 acres of tea garden area, members of the tea sold 10,000 crown tea. The characteristics of such cooperatives is initiated by the tea leading enterprises, give full play to the role of tea cooperatives and the role of a link, a base, farmers, a docking leading enterprises. Leading enterprises and farmers through the cooperatives signed purchase and sale contracts, the organization of coordination of funds and the transfer of production materials and other services to coordinate the interests of both sides, so that enterprises and farmers to achieve a win-win situation between. Such cooperatives to improve the degree of tea farmers and the ability to resist market risk, a stable market and relatively protected prices, increasing the income of tea farmers.

\section{A coalition of tea cooperatives}

In recent years, the tea professional cooperatives have developed rapidly, but the cooperatives are generally small, the majority of the residents of the community, the small cooperation is difficult to adapt to the contradiction between the big market still exists. Therefore, the new cooperation of the cooperative organizations, especially the same tea producing areas of homogeneous, scattered tea professional cooperatives together to form a coalition, help to avoid the vicious competition between cooperatives, and expand their own strength. Tea cooperatives are jointly organized by two or more tea cooperatives, which are jointly organized by mutual 
legal organizations. May, Hubei Province, Xiaochang County Tea Association of professional cooperatives set up by the eight professional cooperatives and two tea enterprises spontaneously composed of a registered capital of 50 million yuan; the current existing area of 7.6 million mu of tea, radiation led more than 36,000 households , Tea processing plant more than 120 , the annual processing capacity of up to 5,000 tons, with an annual output of 2280 tons of finished tea, the output value reached 120 million yuan; the members to provide industrial policies, new varieties of promotion, green cultivation, formula fertilization, Sales and other train services, the formation of "joint society + professional cooperatives + base + farmers" alliance development model..

\section{AN ANALysis of the VERTICAL AlLiance OF TEA Marketing ChanNEl Alliance Mode}

Tea farmers, tea farmers group or small-scale tea professional cooperatives through the horizontal alliance to solve the internal production scale and quality problems. However, the tea professional cooperatives (or associates) need to establish a marketing channel alliance with tea processing enterprises, wholesalers and retail terminals, etc., to solve the problem of sales of tea terminal products. As the tea professional cooperatives (or associates) and processing enterprises, circulation enterprises and retail terminals in the main line of the tea industry chain in different links, with upstream and downstream relations, so by the above-mentioned alliance with the main body of the alliance is a vertical alliance.

\section{A. Tea professional cooperatives (or union) and tea processing enterprises in the vertical alliance}

Tea professional cooperatives (or association) are generally self-built tea processing plant, the members of the production of tea green for the initial processing, production of tea. However, due to the limitations of funds, technology and sales channels, tea processing cooperatives (or cooperatives) to establish the processing capacity of the processing plant is limited, in the tea green picking period, can not meet all the processing needs of members to find out the sales channel demands. Therefore, the tea professional cooperatives (or associates) need to cooperate with the tea processing enterprises to solve the problem of leaf processing and sales. At the same time, tea professional cooperatives (or association) production of wool tea also need to cooperate with the processing enterprises, further finishing. Therefore, in this realistic background, the tea professional cooperatives (or associates) give full play to the role of bridges and ties, to carry out cooperation with the processing enterprises in the form of contracts or equity and enterprises to establish long-term strategic cooperative relations to ensure that tea production Stability, continuity and long-term efficiency, to protect the economic interests of small farmers scattered within the organization and market economy status.

\section{B. Tea professional cooperatives (or affiliates) and wholesalers wholesalers / (market) market alliances}

Tea cooperatives and tea processing enterprises to establish an alliance, can solve the problem of tea and tea sales. However, browish-green and primary tea are primary agricultural products, low value-added products, it is difficult to effectively improve the overall benefits of tea farmers and cooperatives. With the gradual popularization of tea processing machinery and the availability of tea refining technology, most of the tea professional cooperatives (or association) in the production capacity of refined tea, tea processing to complete the whole process, and large-scale production Product "selling hard" problem highlighted. In this context, the tea professional cooperatives (or associates) began to establish a strategic alliance with the strength of the tea wholesalers / market to ensure that the production of refined tea can be circulated and sold, so that the economic benefits of tea farmers and cooperatives can be achieved.

\section{Tea professional cooperatives (or union) and tea retail terminals}

In the entire tea industry chain, the planting link in the tea product value chain in the lowest income, and brand management and sales of the highest income. To tea professional cooperatives as the core of the marketing alliance model operation, the tea professional cooperatives (or association) in order to obtain higher efficiency, in policy support began to take the brand development path. For example, some tea professional cooperatives (or associates) began producing refined tea and registered trademarks to cultivate tea brands. Since then, the tea professional cooperatives (or association) can self-built outlets to sell their own brand of tea, but the direct investment into the store, for no advantage of the advantages of cooperatives, as its main sales channels. Therefore, the tea professional cooperatives (or associates) and tea franchise stores, teahouses, teahouses, restaurants, shopping malls counters, supermarket stores and other retail terminals to establish a coalition, the formation of sales channels to solve the brand development of export sales.

\section{CONCLUSION}

Tea professional cooperatives are recognized by all levels of government to improve the status of tea farmers and bargaining power, and promote tea farmers an important choice and an important way. In the market and the government to encourage the dual role of China's tea professional cooperatives have been rapid development, business model has also been innovative. On the basis of literature review and field investigation, this paper systematically combs the model of tea marketing channel alliance with professional cooperatives as the core, and constructs the overall operation framework of tea marketing channel alliance model with cooperatives as the core, and decomposes the framework For the horizontal alliance and vertical alliance two components, at the same time this article is the extension of the previous literature and development, having some practical significance. 


\section{ACKNOWLEDGMENT}

Author: Song Chen(1972 -), male, Nanping, Fujian, doctoral student, college of economic, Fujian Agriculture and Forestry University, research direction for the tea industry economic management. E-mail:123cs123cs@163.com.

Corresponding author: Jiangfan Yang, professor, Fujian Agriculture and Forestry University, research direction being for the tea industry economy and management.

Program of Foundation: China Oolong Tea Collaborative Innovation Project, 2011(Program Code: K8015H01C).

\section{REFERENCES}

[1] Wu Yannan. China's tea export international competitiveness research [J]. Hubei Social Sciences, 2011 (2): 88-91.

[2] Cai Wenzhu, Liu Hua. Problems and Countermeasures of Agricultural Product Marketing Channel Construction in China [J] .Hubei Agricultural Sciences, 2010, 49 (2): 494-496.

[3] Ji Zhenhu. Play the role of cooperatives to promote tea farmers to increase - remember four tea professional cooperatives survey [China], China Tea, 2015 (9): 15-15.

[4] Qin Zhongchun. A Choice of Institutional Innovation of Farmers' Professional Cooperatives - Based on the Investigation of the Reform of Tea Cooperative in Gu Shang Jin Biluochun, Suzhou [J]. China Rural Economy, 2007 (7): 60-66.

[5] Chen Zhongze, Xie Jijin. Strengthen the management of the implementation of joint-stock system to promote industrial development - remember three green tea professional cooperatives [J]. China Tea, 2005, 27 (4): 35-35.

[6] Meng Fei. Alienation Behavior and Regulation of Leading Enterprises[J]. Journal of Anhui University (Philosophy and Social Sciences), 2014,38(5)145-152. 